\title{
How important are fixed effects and time trends in estimating returns to schooling? Evidence from a replication of Jacobson, Lalonde, and Sullivan, 2005
}

\author{
Susan Dynarski ${ }^{1} \mid$ Brian Jacob $^{1} \mid$ Daniel Kreisman ${ }^{2}$
}

${ }^{1}$ Gerald R. Ford School of Public Policy, University of Michigan, Ann Arbor, Michigan

${ }^{2}$ Department of Economics, Georgia State University, Atlanta, Georgia

Correspondence

Daniel Kreisman, 14 Marietta St. NW

Atlanta, Georgia, 30303.

Email: dkreisman@gsu.edu

\begin{abstract}
Summary
A substantial and rapidly growing literature has developed around estimating earnings gains from 2-year college degrees using administrative data. These papers almost universally employ a person-level fixed-effects strategy to estimate earnings premia net of fixed attributes. We note that the seminal piece on which these papers build-Jacobson, Lalonde, \& Sullivan, Journal of Econometrics, 2005, 125(1-2), 271-304—provides theoretical and empirical evidence for the importance of additionally differencing out individual time trends. The subsequent literature has not followed suit. Through replication we ask whether this matters. We show that it does, and further that these person-level time trends need not be computationally burdensome in large administrative data. We recommend them as a unifying econometric standard for future work.
\end{abstract}

\section{1 | INTRODUCTION}

Estimates of the labor market returns to community college degrees using administrative data have grown dramatically in just the past few years (see Bahr et al., 2015; Bettinger \& Soliz, 2016; Dadgar \& Trimble, 2015; Jepsen, Troske, \& Coomes, 2014; Liu, Belfield, \& Trimble, 2015; Stevens, Kurlander, \& Groz, 2015; Xu \& Trimble, 2016; Zeidenberg, Scott, \& Belfield, 2015). This is due in large part to the availability of statewide longitudinal databases, and in no small part to a resurgence in demand for these programs and associated skills as an alternative to costly 4-year degrees.

These papers, neatly summarized by Belfield and Bailey (2017), almost universally employ a person-level fixed-effects approach to estimate degree attainment "effects" on earnings. While these papers explicitly build on seminal work by Jacobson, Lalonde, and Sullivan (2005a, JLS hereafter), we note a key difference. Whereas JLS estimate a model that includes both individual fixed effects and individual time trends, accounting for "individual-specific heterogeneity that change at a constant rate over time," the subsequent literature has not followed suit, including only the former and omitting the computationally intensive latter. ${ }^{1,2}$

Using administrative data on community college students and their labor market outcomes from Michigan, we ask whether this matters. Replicating the main specification in JLS and comparing it with the current literature, we find that it does for some, though not all, awards. We demonstrate that a straightforward procedure described by JLS based on a Frisch-Waugh-Lovell-style partial regression can be easily employed to reduce the computational burden of including a large number of individual time trends in estimating returns to community college degrees with large administrative

${ }^{1}$ We note that a new working paper, Carruthers and Sanford (2018), employs the model we propose here.

${ }^{2}$ The authors (JLS) also have a companion paper, Jacobson, Scott, and Belfield (2005b), that focuses on policy relevance with more data. Conclusions are similar. 
data. We conclude that, while estimates of returns to community college degrees remain positive with new evidence from Michigan, future work on this timely and economically salient question would be wise to include individual time trends in their empirical exercises as they prove to be econometrically important, computationally feasible, and provide a concise avenue for researchers with disparate information on observable characteristics to estimate identical empirical models without loss of information.

\section{2 | THE FIXED EFFECTS MODEL IN RETURNS TO COMMUNITY COLLEGE}

We begin by describing the model in JLS, which is the richest and most exhaustive in terms of accounting for pre-trends and individual characteristics. Using their notation, the authors estimate the following:

$$
y_{i t}=\alpha_{i}+\omega_{i} t+\gamma_{t}+x_{i t} \beta+\delta_{i t}\left(s_{i}, z_{i}\right)+\tau_{i t}\left(c_{i}, f_{i}, l_{i}, z_{i}\right)+\varepsilon_{i t},
$$

where quarterly earnings $\left(y_{i t}\right)$ depend on an unobserved individual fixed effect $\left(\alpha_{i}\right)$, individual time trends $\left(\omega_{i} t\right)$, and secular quarter fixed effects $\left(\gamma_{t}\right)$. In addition, the model includes time-varying worker characteristics $\left(x_{i t}\right)$, effects of job displacement $\delta_{i t}\left(s_{i}, z_{i}\right)$, which depend on time of displacement $\left(s_{i}\right)$ and individual characteristics $\left(z_{i}\right)$, and the effects of additional schooling $\tau_{i t}\left(c_{i}, f_{i}, l_{i}, z_{i}\right)$, which can depend on worker characteristics, credits earned $c_{i}$, and first and last quarters of enrollment $\left(c_{i}, f_{i}\right)$.

Note that this specification accounts, in a piece-wise manner, for several factors. First, the authors flexibly control for the effects of job displacement, $\delta_{i t}\left(s_{i}, z_{i}\right)$, drawing on earlier work by Jacobson, LaLonde, and Sullivan (1993) showing that workers' earnings decline before layoffs. Note also that JLS restrict their study to mid-career workers with $3+$ years of tenure prior to layoff, likely leaving them with a less heterogeneous group than subsequent studies. In the JLS case, since the econometrician leverages displacement as an impetus for enrollment, all workers have pre-enrollment earnings, thus the authors can control for earnings trends prior to enrollment. When this is not the case, workers are choosing when to (partially) leave the workforce and devote time to (different types of) schooling for reasons unobserved by the econometrician. These factors likely vary over time, within person, and are correlated with program of study, completion, and pre- and post-schooling earnings (trends). Thus the authors also include individual time trends, $\omega_{i} t$. This accounts for the case that growth in earnings prior to, or during, enrollment is correlated with any of award receipt, program of study within award, intensity of enrollment, and their potential outcomes. Adding individual time trends absorbs this heterogeneity. JLS show, as do we, that these trends matter.

Estimating this model, the authors note, might appear to be a computationally heavy task due to the large number of individual fixed effects and individual time trends, that create a cumbersome matrix inversion when individual observations in administrative data often run into the hundreds of thousands. However, in reality this problem is easily overcome by using partial regression, as described by Frisch-Waugh (Frisch \& Waugh, 1933). To demonstrate, begin with a simplified version of Equation 1 above:

$$
y_{i t}=\alpha_{i}+\omega_{i} t+w_{i t} \lambda+\varepsilon_{i t},
$$

where the vector $w_{i t}$ contains all time-varying terms whose coefficients are not individual specific, such as degree receipt, enrollment, or effects of displacement. The authors then create $\tilde{y}_{i t}$ and $\tilde{w}_{i t}$, which are deviations of $y_{i t}$ and $w_{i t}$ from individual specific means and individual time trends. Standard errors are estimated using the well-known version of White (1980), $\operatorname{cov}(\lambda)=\left(\sum \tilde{w}_{i}^{\prime} \tilde{w}_{i}\right)^{-1}\left(\sum \tilde{w}_{i}^{\prime} e_{i} e_{i}^{\prime} \tilde{w}_{i}\right)\left(\sum \tilde{w}_{i}^{\prime} \tilde{w}_{i}\right)^{-1} .^{3}$ In practice there are several ways one could accomplish this. Partial regression would have one first create $\tilde{y}_{i t}=y_{i t}-\alpha_{i}-\omega_{i} t$ and $\tilde{w}_{i t}=w_{i t}-\alpha_{i}-\omega_{i} t$, and then estimate $\tilde{y}_{i t}=\tilde{w}_{i t} \lambda+\varepsilon_{i t}$ to recover the parameter of interest, $\lambda$. Yet one could simplify this even further. Given that the current literature estimates the model with $n-1$ person fixed effects, a procedure with equivalent computational burden would be to first de-mean $y_{i t}$ and $w_{i t}$ to remove the time-invariant fixed effect, creating $\ddot{y}_{i t}=y_{i t}-\bar{y}_{i t}$ and $\ddot{w}_{i t}=w_{i t}-\bar{w}_{i t}$. Then one could estimate $\ddot{y}_{i t}=\omega_{i} t+\ddot{w}_{i t} \lambda+\varepsilon_{i t}$ containing the same number of parameters as the individual fixed-effects model currently used in the literature. ${ }^{4}$

We note these shortcuts, as do the original authors, to demonstrate that the inclusion of individual time trends and the computation of the corresponding standard errors via the two-step procedure is quite feasible. In fact, one no longer need consult any of these procedures offered above at all. Recent advances in the computation of high-dimensional fixed

\footnotetext{
${ }^{3}$ The exact procedure JLS use can be found in Jacobson et al. (2005a, pp. 284-285).

${ }^{4}$ This would require degree-of-freedom adjustments to the standard errors.
} 
effects (Correia, 2016; Guimaraes \& Portugal, 2010; Mittag, 2016) have not only sped up computation time but also now provide user-friendly routines for the estimation of coefficients and corresponding standard errors. ${ }^{5}$ Thus, if researchers have not allowed for individual time trends because they are difficult to implement, we argue that this should not be the case. Whether or not these trends are important is an empirical matter we investigate below.

\section{3 | ECONOMETRIC SPECIFICATION}

In the following we replicate the stylized version of JLS that has become standard in the literature, many of which are based on Jepsen et al.'s (2014) replication of JLS using data from Kentucky, and compare this to the full model to test whether these time-varying trends matter. We take the following as the standard specification:

$$
y_{i t}=\alpha_{i}+\underbrace{\operatorname{AWARD}_{i t} \Gamma_{j}+W_{i t} \Lambda+X_{i} t \beta+\tau_{t}}_{\text {Sub-components of } w_{i t} \lambda \text { in Equation } 2}+\varepsilon_{i t},
$$

where $y_{i t}$ is real (2011 dollars) quarterly earnings for person $i$ in quarter $t$, and $\alpha_{i}$ is an individual fixed effect. This is the current literature's analogue of JLS's simplified model shown in Equation 2. For clarification of the difference in covariates, we have split $w_{i t} \lambda$ from Equation 2 into four parts. The first is a vector of three degree indicators, $\mathrm{AWARD}_{i t}$, set to unity if individual $i$ has received $j$ as of quarter $t$ for $j=$ short certificate, certificate, and associate degree. In addition, AWARD $_{i t}$ includes an indicator for exiting schooling set equal to one for all post-schooling quarters and a nonlinear post-schooling trend equal to the reciprocal of quarters since exiting and set to zero before exiting schooling. This post-schooling trend is then interacted with each AWARD category. This mimics JLS's parametrization of the nonlinear trajectory earnings take post schooling. In this case, the coefficient vector $\Gamma_{j}$ represents the quarterly return to earning award $j$ with those enrolling but earning no award as the reference group. ${ }^{6}$

Next is a vector of time-varying worker attributes, $W_{i t}$. This vector contains indicators for the four quarters leading to first enrollment to account for Ashenfelter-type pre-enrollment earnings "dips," indicators set equal to one in each quarter $i$ was enrolled interacted with college type (2- and 4-year) to account for earnings declines due to labor market separation, and interactions between enrollment in each college type and ultimate degree received to account for differential separation from the workforce for degree earners. Third, the vector $X_{i} t$ is a set of interactions between a common linear time trend, $t$, and fixed individual characteristics, including: interactions between race and gender, whether students ever received Pell or student loans, the number of remedial and non-remedial credits attempted in the first term to proxy for intensity and degree intentions, and remedial placement scores in English and mathematics including indicators if these scores are missing. This is meant to absorb time-varying heterogeneity in earnings across factors correlated with the likelihood of degree receipt in lieu of individual time trends. Lastly, $\tau_{t}$ are secular quarter indicators and $\varepsilon_{i t}$ contains all other information.

Note that these parameters are an analogue of the main specification in JLS stylized to the current literature. First, the pre-enrollment dips, $\delta_{i t}\left(s_{i}, z_{i}\right)$ in JLS, are simplified as we and others do not focus on separated workers; we show later that these dips are nearly absent in our data. Moreover, they are not interacted with worker characteristics as in the original article. Second, the model accounts for time costs of enrollment by interacting ultimate degree with indicators for enrolled quarters, whereas JLS use credits earned during enrollment averaged over the entire enrollment period since they are estimating returns to credits as opposed to degrees. Both cases are meant to account for intensity weighted investment in schooling over work during the enrollment period. The key remaining difference is that individual time trends in JLS, $\omega_{i} t$, are replaced with an interaction between a common time trend and fixed individual characteristics, $X_{i} t$ in the model above. This is not a trivial omission as we should be concerned with heterogeneity in growth trends that might be correlated with either the likelihood of earning a degree, time to degree among degree recipients, field of study within degree class, or even the degree to which workers separate from the labor force during schooling. In our replication we compare the above model to one that replaces the trends and trend interactions with individual time trends as in JLS. The model then becomes

$$
y_{i t}=\alpha_{i}+\omega_{i} t+\operatorname{AWARD}_{i t} \Gamma_{j}+W_{i t} \Lambda+\tau_{t}+\varepsilon_{i t}
$$

\footnotetext{
${ }^{5}$ See Bai (2009) for a more general discussion of interactive fixed-effects models.

${ }^{6}$ Note that we omit all respondents who ever attend a 4-year school, thus eliminating from the returns to an AA the option value of attempting a bachelor's degree.
} 
TABLE 1 A comparison of community colleges

\begin{tabular}{|c|c|c|c|}
\hline & $\begin{array}{l}5 \text { sample } \\
\text { institutions }\end{array}$ & $\begin{array}{l}\text { All other MI } \\
\text { institutions }\end{array}$ & $\begin{array}{l}\text { All US } \\
\text { institutions }\end{array}$ \\
\hline \multicolumn{4}{|l|}{ Percentages } \\
\hline Female & 57 & 61 & 60 \\
\hline Non-white & 22 & 26 & 36 \\
\hline Full time & 38 & 39 & 46 \\
\hline Traditional & 8 & 11 & 14 \\
\hline \multicolumn{4}{|l|}{ Dollars } \\
\hline Tuition (in district) & $\$ 1,902$ & $\$ 2,025$ & $\$ 2,535$ \\
\hline Tuition (in state) & $\$ 2,995$ & $\$ 3,120$ & $\$ 2,939$ \\
\hline \multicolumn{4}{|l|}{ Counts } \\
\hline Number of schools & 5 & 25 & 1,057 \\
\hline Average enrollment & 13,150 & 6,271 & 5,537 \\
\hline Total enrollment & 65,750 & 156,769 & $5,559,469$ \\
\hline
\end{tabular}

Note. Statistics from IPEDS (2006). Sample is public and not-for-profit 2-year degree granting institutions.

Should these individual fixed effects not matter, we should expect statistically similar estimates in returns to degrees with and without their inclusion.

Given variation in the exact specification of the model above across studies, and large variation in estimate returns to to awards, Belfield and Bailey (2017) ask how much estimates of the above model (a) rely on the inclusion of the person-level fixed effect, which may not be feasible for researchers without access to large administrative databases, (b) are sensitive to other functional form assumptions, such as higher-order time trends, controlling for pre-enrollment "dips," or interactions between time trends and demographic characteristics, and/or (c) are sensitive to different samples and definitions. Their primary analysis sample uses data from North Carolina, and they limit their analysis to earnings gains from an associate degree. ${ }^{7}$ They augment this by detailing the subtle yet important specification and sampling differences across many of the studies described above and others. Ultimately, they conclude that even individual fixed effects have little impact on estimates and that the full fixed-effects model is robust to most sampling restrictions and functional form assumptions, with some exceptions (the handling of missing wages, transfer students, and modeling of time trends). We point out that many of the heterogeneity, trend, and earnings "dip" concerns these various specifications address are lessened or negated by differencing out individual trends. Moreover, there is an added advantage of creating uniformity across studies faced with different available data, as the entire vector $X_{i} t$ is eliminated, obviating the need to selectively choose elements in the $X$ vector.

\section{4 | DATA AND SAMPLE}

Our study was initiated by the receipt of student records from five public, degree-granting Michigan community colleges for all students enrolling in or after the fall semester of 2001-2011. These five institutions represent approximately 40\% of all students in Michigan's public and not-for-profit 2-year schools. Table 1 shows basic summary statistics comparing our schools to other institutions in Michigan and the USA.

These data include student demographics, applications for and receipt of financial aid, scores from remediation placement tests, transcripts from each term attended, and a record of each award received including field of study. In order to account for post-secondary enrollment prior and subsequent to enrollment in our five institutions, including in 4-year colleges, we match these student records to the National Student Clearinghouse database (NSC). Labor market outcomes are taken from the state of Michigan's unemployment insurance records. These indicate gross quarterly earnings for individuals in our sample between quarter 2, 1998 and quarter 2, 2011. These records only include earnings in the state of Michigan and do not include self-employment. On the recommendation of officials from the Michigan Department of Licensing and Regulatory Affairs, who collect and maintain the Unemployment Insurance (UI) data, we recoded all nominal quarterly earnings equal to or less than $\$ 10$ to $\$ 0$ as these are likely misreported. ${ }^{8}$

${ }^{7}$ Belfield and Bailey (2017) incorporate concerns about the fixed-effects model similar to those raised here from Dynarski, Jacob, and Kreisman (2016). ${ }^{8}$ This is similar to our own work on returns in Michigan (Bahr et al., 2015) and an earlier version of this paper focusing on fixed effects (Dynarski et al., 2016). 
TABLE 2 Summary statistics, by degree

\begin{tabular}{|lllll} 
& No degree & Short cert. & Cert. & Assoc. \\
\hline Age first enrolled & 30.3 & 31.1 & 31.9 & 30.9 \\
\hline White & 0.61 & 0.53 & 0.72 & 0.75 \\
Non-white & 0.30 & 0.45 & 0.24 & 0.20 \\
\hline Race missing & 0.10 & 0.03 & 0.05 & 0.06 \\
\hline Ever Pell & 0.27 & 0.41 & 0.29 & 0.36 \\
\hline Ever loans & 0.05 & 0.19 & 0.10 & 0.06 \\
Non-remedial cred. 1st term & 4.76 & 5.34 & 7.15 & 6.87 \\
\hline Remedial cred, 1st term & 1.43 & 0.77 & 1.09 & 1.11 \\
\hline Emp. yr. prior to enroll & 0.67 & 0.75 & 0.76 & 0.68 \\
\hline Earn yr. prior to enroll & 4,660 & 3,513 & 5,425 & 4,136 \\
\hline English score $(Z)$ & 0.00 & -0.11 & 0.13 & 0.51 \\
\hline Math score $(Z)$ & -0.37 & -0.36 & -0.35 & 0.07 \\
\hline Missing English score & 0.59 & 0.39 & 0.62 & 0.58 \\
\hline Missing math score & 0.57 & 0.46 & 0.64 & 0.53 \\
\hline Observations & 27,085 & 379 & 870 & 2,659 \\
\hline
\end{tabular}

Note. Sample consists of first-time college students aged 21-45 at entry, who enrolled in one of our five institutions between 2001 and 2009, who have non-missing age and gender, and who never subsequently enrolled in a 4-year school.

We limit our sample to first-time college students. ${ }^{9}$ In order to allow for the accumulation of earnings before enrollment, and for the accumulation of earnings after exit, we further restrict our working sample to individuals who first enrolled in our colleges between fall 2002 and fall 2007, to those who were between age 21 and 45 at first enrollment and between ages 17 and 65 when working, and to those who did not take any coursework after mid-2009. We also restrict our analysis to students who did not attend a 4-year school after entering community college. This has the effect of evaluating the effect of a terminal 2-year degree. Lastly, we omit the few students with missing date of birth and gender. Table 2 shows summary statistics by ultimate degree.

\section{5 | RESULTS}

To give a visual sense of trends and gains from awards, we display earnings trends by degree receipt relative to last quarter before enrollment and first quarter after exit (defined as after last enrollment for non-degree earners or after receiving the highest award for award recipients) in Figure 1. Thus the break between Last and First is the enrollment period. Note that in panel A we see little evidence of earnings dips prior to enrollment, that we see large unconditional gains for all award recipients, and little difference for non-degree earners. In panel B we display the same trends but showing median, rather than mean, quarterly earnings. Here we see a striking difference. Pre-enrollment median earnings far are less than half of mean earnings, while post-schooling earnings for award recipients converge on post-schooling means. Yet post-schooling median earnings for non-award earners converge to zero. This pattern suggests wide heterogeneity in earnings (trends) and returns to schooling even among award earners.

Turning to our main result, Table 3 shows results from Equation 3 above sequentially adding elements. We begin in column 1 by including only degree indicators and quarter fixed effects to show raw differences, observing a near $\$ 2,000$ gain from a certificate and about $\$ 1,500$ from an associate degree. In column 2 we add our full vector of fixed person-level covariates, $X_{i}$, in addition to a full set of interactions between age, school, and enrollment cohort, a quadratic term in age, and our vector of common time-varying elements, $W_{i t}$, which include enrollment covariates and controls for common pre-enrollment dips. The result is an increase in the estimated return to a short certificate from null to about $\$ 550$, and an increases of about $\$ 200$ for each of certificates and associate degrees, though we cannot reject that estimates for the latter two are different from results in column 1. In column 3 we then add a linear time trend and interact it with the full

${ }^{9}$ Note that our NSC records date back to 1995 , so it is possible that some students enrolled prior to 1995 and then did not enroll again until they entered our schools. 


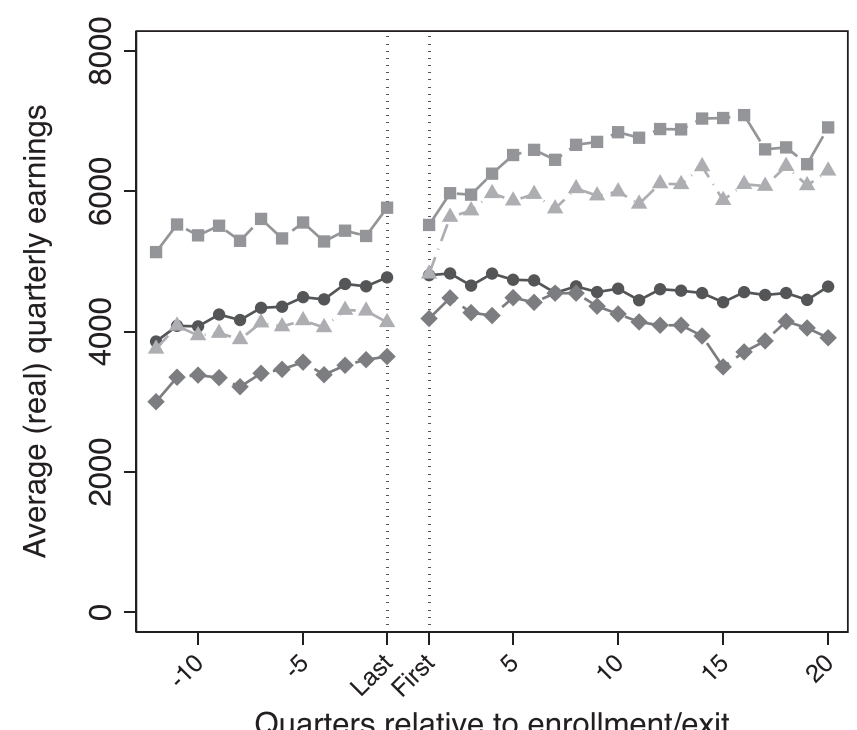

Quarters relative to enrollment/exit

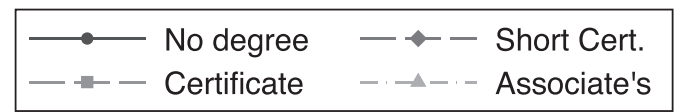

(a) Mean Quarterly Earnings

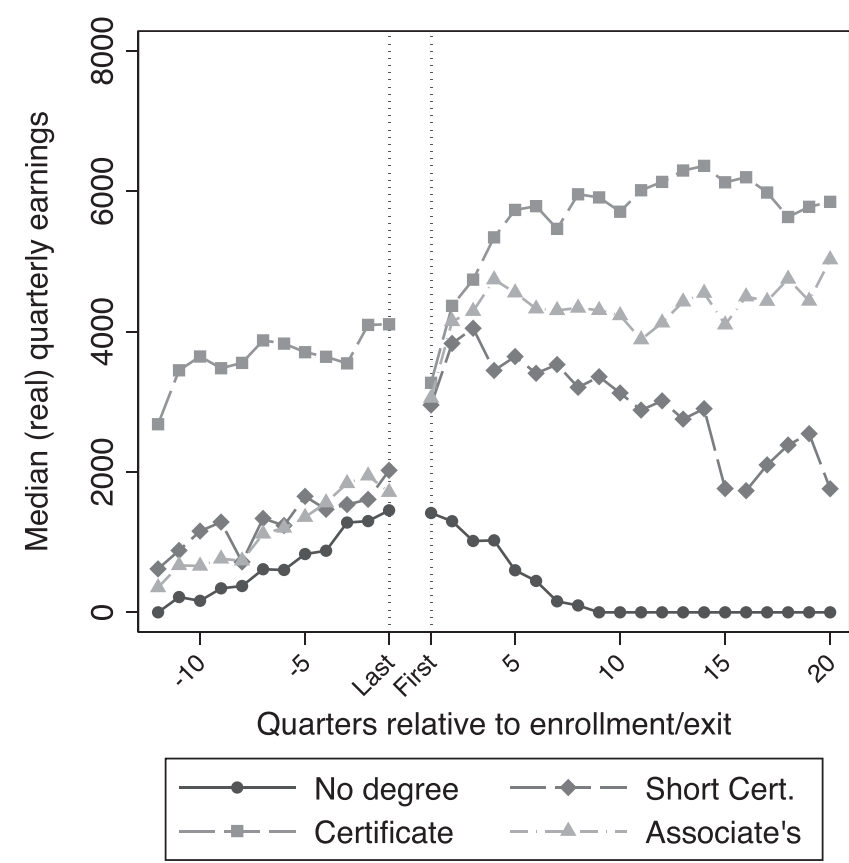

(b) Median Quarterly Earnings

FIGURE 1 Mean and median earnings, relative to school start and exit. Plots show mean (a) and median (b) quarterly earnings by eventual highest degree earned relative to last quarter before enrollment (last) and first quarter after enrollment (first). Enrollment end is defined as last quarter enrolled for non-award earners and quarter in which highest degree awarded is earned for degree recipients

vector of fixed covariates. We find that results are virtually unchanged, suggesting that this interaction is soaking up little variation in our sample. In column 4 we model post-schooling earnings growth interacted with degree receipt, where the post trend is the reciprocal of quarters since degree receipt. Again, modest increases in estimated returns to certificates and associate degrees, of approximately $\$ 300$ each, but not for short certificates, suggests that earnings rise steeply in the first quarters post schooling. We take a moment here to note an additional, though small, difference between the original JLS article and subsequent work. JLS model common post-degree returns using the reciprocal of quarters since graduation where subsequent work largely uses linear or quadratic trends. Misspecification here could potentially bias 
TABLE 3 Earnings specifications

\begin{tabular}{|c|c|c|c|c|c|c|}
\hline & (1) & (2) & (3) & (4) & (5) & (6) \\
\hline Short cert. & $\begin{array}{l}-295.5 \\
(208.1)\end{array}$ & $\begin{array}{l}525.0^{* *} \\
(206.8)\end{array}$ & $\begin{array}{l}551.5^{* * *} \\
(208.4)\end{array}$ & $\begin{array}{l}556.5^{* * *} \\
(232.9)\end{array}$ & $\begin{array}{l}607.5^{* * *} \\
(206.5)\end{array}$ & $\begin{array}{l}822.5^{* * * *} \\
(235.2)\end{array}$ \\
\hline Certificate & $\begin{array}{l}1959.7^{* * *} \\
(227.4)\end{array}$ & $\begin{array}{l}2168.7^{* * *} \\
(213.4)\end{array}$ & $\begin{array}{l}2134.9^{* * *} \\
(215.3)\end{array}$ & $\begin{array}{l}2428.4^{* * *} \\
(252.2)\end{array}$ & $\begin{array}{l}904.2^{* * *} \\
(205.3)\end{array}$ & $\begin{array}{l}806.9^{* * *} \\
(193.0)\end{array}$ \\
\hline Associate & $\begin{array}{l}1480.8^{* * *} \\
(132.9)\end{array}$ & $\begin{array}{l}1655.9^{* * *} \\
(129.6)\end{array}$ & $\begin{array}{l}1634.2^{* * *} \\
(131.4)\end{array}$ & $\begin{array}{l}1930.5^{* * *} \\
(162.2)\end{array}$ & $\begin{array}{l}1876.7^{* * *} \\
(142.0)\end{array}$ & $\begin{array}{l}2343.8^{* * *} \\
(150.8)\end{array}$ \\
\hline Post & & & & $\begin{array}{l}298.2^{* * * *} \\
(81.11)\end{array}$ & $\begin{array}{l}-25.49 \\
(53.52)\end{array}$ & $\begin{array}{l}-34.63 \\
(55.23)\end{array}$ \\
\hline Post-trend & & & & $\begin{array}{l}297.8^{* * *} \\
(76.40)\end{array}$ & $\begin{array}{l}516.2^{* * * *} \\
(59.53)\end{array}$ & $\begin{array}{l}310.4^{* * *} \\
(51.32)\end{array}$ \\
\hline Post-trend $\times$ S. Cert. & & & & $\begin{array}{l}-79.13 \\
(348.9)\end{array}$ & $\begin{array}{l}56.94 \\
(303.0)\end{array}$ & $\begin{array}{l}-29.37 \\
(291.9)\end{array}$ \\
\hline Post-trend $\times$ Cert & & & & $\begin{array}{l}-1640.6^{\text {*** }} \\
(353.1)\end{array}$ & $\begin{array}{l}-1206.9^{* * *} \\
(320.5)\end{array}$ & $\begin{array}{l}-1061.3^{* * *} \\
(286.5)\end{array}$ \\
\hline Post-trend $\times$ Assoc. & & & & $\begin{array}{l}-1349.4^{* * *} \\
(192.7)\end{array}$ & $\begin{array}{l}-1446.0^{* * *} \\
(166.6)\end{array}$ & $\begin{array}{l}-1794.9^{* * *} \\
(148.6)\end{array}$ \\
\hline$\omega_{i} t$ & & & & & & $x$ \\
\hline$\alpha_{i}$ & & & & & $x$ & $x$ \\
\hline$X_{i} t$ & & & $x$ & $x$ & $x$ & \\
\hline$X_{i}$ & & $x$ & $x$ & $x$ & & \\
\hline$W_{i t}$ & & $\times$ & $\times$ & $x$ & $x$ & $x$ \\
\hline$\tau_{t}$ & $x$ & $x$ & $x$ & $x$ & $x$ & $x$ \\
\hline$n$ & 30,993 & 30,993 & 30,993 & 30,993 & 30,993 & 30,993 \\
\hline$N$ & $1,609,090$ & $1,609,090$ & $1,609,090$ & $1,609,090$ & $1,609,090$ & $1,609,090$ \\
\hline
\end{tabular}

Note. Dependent variable is quarterly earnings in real 2011 dollars. Post-trend is the reciprocal of quarters since exiting schooling. $W_{i t}$ are time-varying indicators for enrollment and pre-enrollment dips. $X_{i}$ are fixed person-level covariates including age-college-cohort fixed effects. $t$ is a linear time trend and $\tau_{t}$ are secular quarter indicators. $\alpha_{i}$ is a person fixed effect and $\omega_{i} t$ is an individual time trend. All model parameters are described in Section 3. Standard errors clustered on individuals in parentheses $\left({ }^{*} p<0.10 ; * * p<0.05 ; * * *<0.01\right)$.

results downward. Column 5 then replicates the full model from Equation 3 by adding individual fixed effects as it is commonly employed post JLS.

We find that adding individual fixed effects results in a large and significant estimate decrease for certificate earners, by well over half, and a smaller increase for short certificate earners, which is not statistically different from the model without fixed effects. Note also that we find that estimates of returns to associate degrees are largely unchanged. The lack of impact of the individual fixed effect for associate earners, and stability of estimates across specifications, is a confirmation of results in Jepsen et al. (2014) and Belfield and Bailey (2017). In addition, our estimate of returns to associate degrees are on par with their findings and their summary of others in the literature, suggesting that we are providing a reliable replication. Yet, that we see large and significant changes to estimates of returns to certificates by adding fixed effects suggests that Belfield and Bailey's claim that estimates are robust to fixed effects across the literature may not extend beyond associate degrees.

In column 6 we then estimate Equation 4 by adding individual time trends to Equation 3 and dropping the now redundant $X_{t} t$ vector. Here we find a modest nominal impact on short certificates and little impact on certificates, of approximately -200 and +100 , or $11 \%$ and $35 \%$ respectively, in the main effects, though we cannot jointly distinguish these coefficients from those in model 5 . Yet, we do find a near $\$ 500$, or roughly $25 \%$, increase in estimated returns to associate degrees by including the individual time trends, in addition to a steeper growth rate to the earnings profile. JLS reach the same conclusion. They show that estimated earnings gains increase with the inclusion of individual time trends, arguing this is evidence that after accounting for observable factors, workers who earn more credits (or earn awards in our case) had flatter earnings growth prior to enrollment (p. 278). The differences between these models are both statistically significant and economically meaningful. To further the latter point we calculate the present value of the difference in estimated earnings streams between models 5 and 6 , discounted at a rate of $5 \%$ over 10 years. The discounted net present 
TABLE 4 Main earnings specifications, by gender

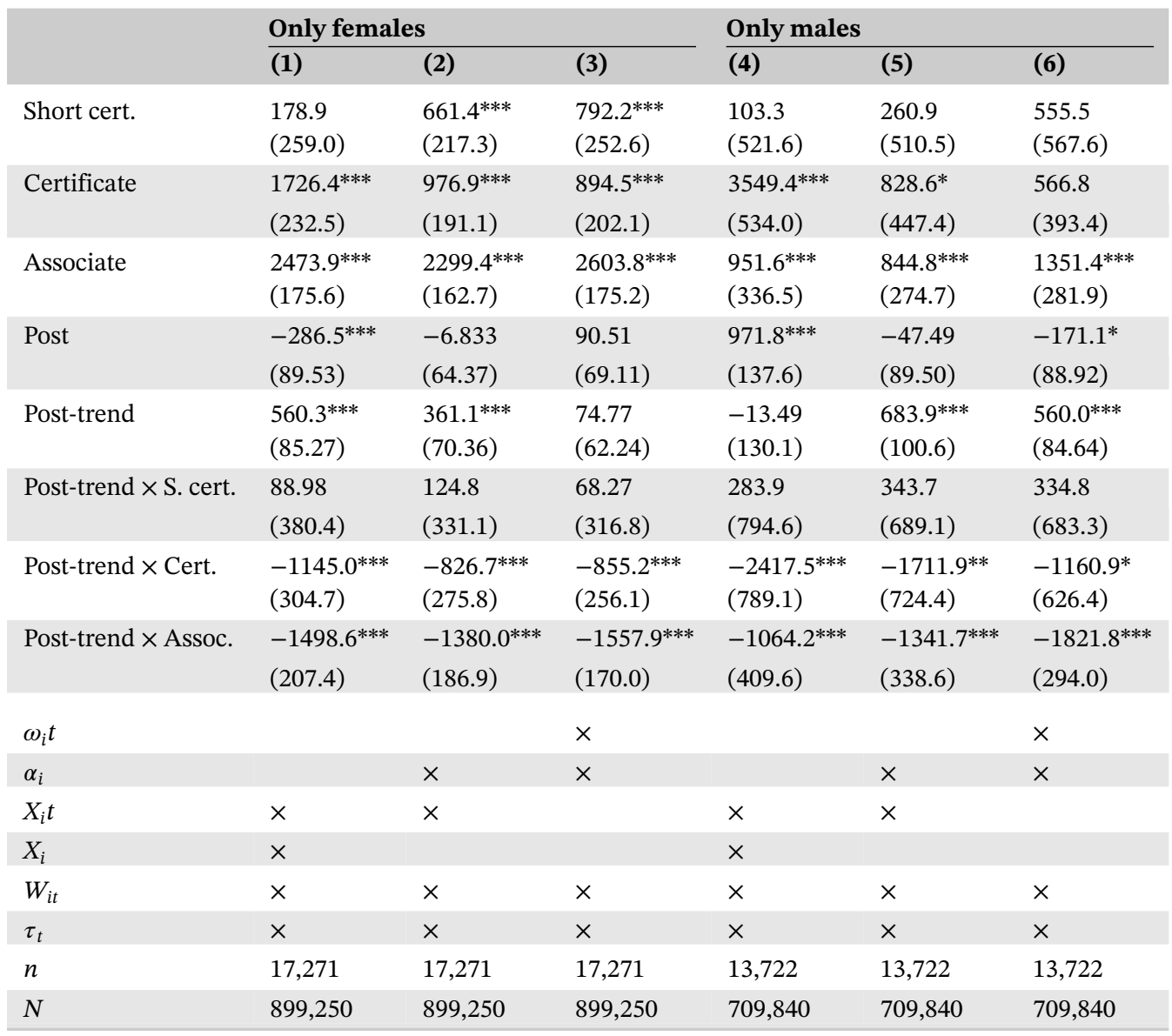

Note. Table replicates main specifications, columns 4, 5 and 6 from Table 3, separately by gender. Sample in columns 1-3 is females only, and is males only in columns 4-6. No other changes are made. Dependent variable is quarterly earnings in real 2011 dollars. Post-trend is the reciprocal of quarters since exiting schooling. $W_{i t}$ are time-varying indicators for enrollment and pre-enrollment dips. $X_{i}$ are fixed person-level covariates including age-college-cohort fixed effects. $t$ is a linear time trend and $\tau_{t}$ are secular quarter indicators. $\alpha_{i}$ is a person fixed effect and $\omega_{i} t$ is an individual time trend. All model parameters are described in Section 3. Standard errors clustered on individuals in parentheses $\left({ }^{*} p<0.10 ;{ }^{* *} p<0.05 ; *^{* *} p<0.01\right)$.

value comes to more than $\$ 7,000$, roughly equal to 2 years of tuition and fees for in-state public community colleges (Ma $\&$ Baum, 2016). Nonetheless, we note that estimated annual returns to community college degrees in Michigan remain positive and persistent, of the order of about $\$ 3,200$ for (short) certificates, and over $\$ 9,000$ for associate degrees. We caveat these results by noting that we use data in only one state, and results might not carry over to different settings. We also note that by virtue of a large sample we are able to detect relatively modest differences across specifications, where researchers with fewer data points might not find differences across specifications.

For exposition, we estimate two final sets of analyses. First, we replicate columns 4-6 of Table 3 separately by gender in Table 4 to align ourselves better with the existing literature. We find that the importance of the individual time trend is largely limited to males. The gains associated with certificates for males declines from $\$ 828$ to $\$ 566$, with the latter not distinguishable from zero (or from $\$ 828$ ). The gain associated with an AA degree increases from $\$ 845$ to $\$ 1,351$ when person-level trends are added. The change for women is much smaller, from $\$ 2,299$ to $\$ 2,603$.

As a final exercise, we explore the possibility that individual time trends need not be linear by including first a second-order polynomial trend, and then by estimating two separate individual trends: one before and one after college. With column 1 of Table 5 repeating our main specification including linear person trends, column 2 adds a quadratic term and column 3 estimates two separate trends. Estimates in column 2 vary considerably from those in the linear specification, though they are not statistically different from those in column 1. In column 3 we find larger differences, where the main effects all decrease, suggesting that individual slope differences might be affected by additional schooling as well as common trends. In either case, we conduct these exercises to demonstrate that the Frisch-Waugh procedure can be applied to any number of fixed effects or trends. The degree to which differencing out individual time trends, or, say, the 
TABLE 5 Additional earnings specifications

\begin{tabular}{|c|c|c|c|}
\hline & (1) & (2) & (3) \\
\hline Short cert. & $\begin{array}{l}822.5^{* * *} \\
(235.2)\end{array}$ & $\begin{array}{l}611.0^{* * *} \\
(226.7)\end{array}$ & $\begin{array}{l}701.0^{* * *} \\
(257.8)\end{array}$ \\
\hline Certificate & $\begin{array}{l}806.9^{* * *} \\
(193.0)\end{array}$ & $\begin{array}{l}952.5^{* * *} \\
(183.2)\end{array}$ & $\begin{array}{l}577.7^{* *} \\
(238.2)\end{array}$ \\
\hline Associate & $\begin{array}{l}2343.8^{* * *} \\
(150.8)\end{array}$ & $\begin{array}{l}2561.3^{* * *} \\
(159.2)\end{array}$ & $\begin{array}{l}2169.2^{* * *} \\
(191.7)\end{array}$ \\
\hline Post & $\begin{array}{l}-34.63 \\
(55.23)\end{array}$ & $\begin{array}{l}-144.5^{* * *} \\
(51.12)\end{array}$ & $\begin{array}{l}-85.15 \\
(57.07)\end{array}$ \\
\hline Post-trend & $\begin{array}{l}310.4^{* * *} \\
(51.32)\end{array}$ & $\begin{array}{l}337.0 * * * \\
(49.58)\end{array}$ & $\begin{array}{l}155.9^{* * *} \\
(53.87)\end{array}$ \\
\hline Post-trend $\times$ S. cert. & $\begin{array}{l}-29.37 \\
(291.9)\end{array}$ & $\begin{array}{l}246.2 \\
(285.2)\end{array}$ & $\begin{array}{l}179.0 \\
(313.3)\end{array}$ \\
\hline Post-trend $\times$ Cert. & $\begin{array}{l}-1061.3^{* * *} \\
(286.5)\end{array}$ & $\begin{array}{l}-942.6^{* * *} \\
(267.0)\end{array}$ & $\begin{array}{l}-607.4^{*} \\
(314.7)\end{array}$ \\
\hline Post-trend $\times$ Assoc. & $\begin{array}{l}-1794.9^{* * *} \\
(148.6)\end{array}$ & $\begin{array}{l}-1755.2^{* * *} \\
(151.6)\end{array}$ & $\begin{array}{l}-1437.8^{* * *} \\
(178.5)\end{array}$ \\
\hline$\omega_{i}\left(t_{\text {pre }}, t_{\text {post }}\right)$ & & & $x$ \\
\hline$\omega_{i} t^{2}$ & & $x$ & \\
\hline$\omega_{i} t$ & $x$ & $\times$ & \\
\hline$\alpha_{i}$ & $x$ & $x$ & $x$ \\
\hline$W_{i t}$ & $x$ & $x$ & $x$ \\
\hline$\tau_{t}$ & $x$ & $x$ & $x$ \\
\hline$n$ & 30,993 & 30,993 & 30,993 \\
\hline$N$ & $1,609,090$ & $1,609,090$ & $1,609,090$ \\
\hline
\end{tabular}

Note. Column 1 replicates specification 6 in Table 3. Dependent variable is quarterly earnings in real 2011 dollars. Post-trend is the reciprocal of quarters since exiting schooling. $W_{i t}$ are time-varying indicators for enrollment and pre-enrollment dips and $\tau_{t}$ are secular quarter indicators. $\alpha_{i}$ is a person fixed effect, $\omega_{i} t$ is an individual time trend or quadratic $\left(t^{2}\right)$, and $\omega_{i}\left(t_{\text {pre }}, t_{\text {post }}\right)$ are separate individual trends pre- and post-schooling. All model parameters are described in Section 3. Standard errors clustered on individuals in parentheses $\left({ }^{*} p<0.10 ;{ }^{* *} p<0.05 ;{ }^{* * *} p<0.01\right)$.

importance of higher-order polynomials in these trends, will likely vary with economic conditions and the demographic composition of the sample. Nonetheless, including these trends in econometric specifications has a very useful advantage: it creates uniformity across studies faced with different available information about workers' characteristics, potentially facing different local economic conditions. This has the added advantage of creating uniformity across the many existing, in-progress, and future studies that make use of administrative panel data as described here.

\section{6 | DISCUSSION AND SUGGESTIONS}

Community colleges have become an increasingly important part of the American education system. Yet, estimating the economic return to these programs is an ongoing process. Because many of the quasi-experimental methods employed to estimate returns to 4-year colleges do apply in the 2-year case, researchers have relied on large administrative panels, employing a fixed-effects model to difference out unobserved differences between degree earners and non-completers. We note that the seminal piece in this literature - Jacobson et al. (2005a)—cautions that time-varying unobserved heterogeneity is a real concern. The authors point out that demeaning individual time trends in addition to fixed attributes is warranted both theoretically and empirically. The many subsequent papers have not followed suit, quite possibly due to the computational burden of high-dimension fixed effects in large panels. Through replication, we show that the same Frisch-Waugh procedure outlined in Jacobson et al. (2005a) makes this problem tractable and points readers to recent advances in the computation of multiple high-dimension fixed effects. 
Ultimately we determine that both the fixed effects and time trends matter. The trends matter most for associate degree earners, suggesting that in our data long-run returns might be under-evaluated by as much as $25 \%$. This finding concurs with Jacobson et al., who find that earnings growth prior to schooling was negatively correlated with schooling investments. We also note that our exercises add to the empirical body of research suggesting economically large and statistically significant earnings gains to earning a community college award, of the order of about $\$ 2,300$ per quarter (nearly $\$ 10,000$ per year) for associate earners, and about $\$ 800$ ( $\$ 3,200$ per year) per quarter for certificate holders. These results are on a par, though at the high end, of other work in the literature.

Importantly, we point out that there is a wide variation in model specification across the many studies currently in print or in progress. This is in large part due to variation in what is included in the data (e.g., Jacobson et al. know workers' occupations). Since the inclusion of individual fixed effects and trends differences out (trends in) these factors, specifying a model with both will obviate this difference across studies. Moreover, our study, just as Jacobson et al. previously, is agnostic as to the relationship between these trends and investments in schooling. Rather, we treat it as an empirical question that might vary with (local) economic conditions, within or across states and over time. In this sense, as the literature moves forward, we suggest that subsequent researchers have good reason and convenient means to return to the model that started the literature.

\section{ACKNOWLEDGMENTS}

This research was supported by the Institute of Education Sciences, US Department of Education, through Grant R305C110011 to Teachers College, Columbia University. The opinions expressed are those of the authors and do not represent views of the Institute or the US Department of Education. We owe thanks to Joanna Frye, Alfredo Sosa, Francie Streich, Mark Wiederspan, and Chris Zbrozek for research assistance. We also thank Bob Lalonde for his mentorship.

\section{REFERENCES}

Bahr, P. R., Dynarski, S., Jacob, B., Kreisman, D., Sosa, A., \& Wiederspan, M. (2015). Labor market returns to community college awards: Evidence from michigan. (Technical Report, CAPSEE Working Paper). New York, NY: Center for Analysis of Postsecondary Education and Employment.

Bai, J. (2009). Panel data models with interactive fixed effects. Econometrica, 77(4), 1229-1279.

Belfield, C. R., \& Bailey, T. (2017). The labor market returns to sub-baccalaureate college: A review. (Technical Report, CAPSEE Working Paper). New York, NY: Center for Analysis of Postsecondary Education and Employment.

Bettinger, E., \& Soliz, A. (2016). Returns to vocational credentials: Evidence from Ohio's community and technical colleges. (Technical Report, CAPSEE Working Paper). New York, NY: Center for Analysis of Postsecondary Education and Employment.

Carruthers, C. K., \& Sanford, T. (2018). Way Station or Launching Pad? Unpacking the Returns to Adult Technical Education. Journal of Public Economics, 165, 146-159.

Correia, S. (2016). Linear models with high-dimensional fixed effects: An efficient and feasible estimator. (Working paper). Retrieved from http://scorreia.com/research/hdfe.pdf

Dadgar, M., \& Trimble, M. J. (2015). Labor market returns to sub-baccalaureate credentials: How much does a community college degree or certificate pay? Educational Evaluation and Policy Analysis, 37(4), 399-418.

Dynarski, S., Jacob, B., \& Kreisman, D. (2016). The fixed-effects model in returns to schooling and its application to community colleges: A methodological note. (Working Paper). New York, NY: Center for Analysis of Postsecondary Education and Employment.

Frisch, R., \& Waugh, F. V. (1933). Partial time regressions as compared with individual trends. Econometrica, 1, 387-401.

Guimaraes, P., \& Portugal, P. (2010). A simple feasible alternative procedure to estimate models with high-dimensional fixed effects. Stata Journal, 10(4), 628-649.

Jacobson, L. S., LaLonde, R. J., \& Sullivan, D. G. (1993). Earnings losses of displaced workers. American Economic Review, 83(4), 685-709.

Jacobson, L., LaLonde, R., \& Sullivan, D. (2005a). Estimating the returns to community college schooling for displaced workers. Journal of Econometrics, 125(1-2), 271-304.

Jacobson, L., LaLonde, R., \& Sullivan, D. (2005b). The impact of community college retraining on older displaced workers: Should we teach old dogs new tricks? Industrial and Labor Relations Review, 58(3), 398-415.

Jepsen, C., Troske, K., \& Coomes, P. (2014). The labor-market returns to community college degrees, diplomas, and certificates. Journal of Labor Economics, 32(1), 95-121.

Liu, V. Y., Belfield, C. R., \& Trimble, M. J. (2015). The medium-term labor market returns to community college awards: Evidence from North Carolina. Economics of Education Review, 44, 42-55.

Ma, J., \& Baum, S. (2016). Trends in Community Colleges: Enrollment, Prices, Student Debt, and Completion. (College Board Research Brief). New York, NY: College Board.

Mittag, N. (2016). A simple method to estimate large fixed effects models applied to wage determinants and matching. (IZA Working Paper No.10447). Bonn, Germany: Institute of Labor Economics. 
Stevens, A. H., Kurlander, M., \& Groz, M. (2015). Career technical education and labor market outcomes: Evidence from california community colleges. (NBER Working Paper 21137). Cambridge, MA: National Bureau of Economic Research.

White, H. (1980). A heteroskedasticity-consistent covariance matrix estimator and a direct test for heteroskedasticity. Econometrica, 48(4), $817-838$.

Xu, D., \& Trimble, M. (2016). What about certificates? Evidence on the labor market returns to nondegree community college awards in two states. Educational Evaluation and Policy Analysis, 38(2), 272-292.

Zeidenberg, M., Scott, M., \& Belfield, C. (2015). What about the non-completers? the labor market returns to progress in community college. Economics of Education Review, 49, 142-156.

How to cite this article: Dynarski S, Jacob B, Kreisman D. How important are fixed effects and time trends in estimating returns to schooling? Evidence from a replication of Jacobson, Lalonde, and Sullivan, 2005. J Appl Econ. 2018;33:1098-1108. https://doi.org/10.1002/jae.2653 